la Victoria, entre otros ejemplos, cuyas referencias concretas me impide dar lo limitado de este espacio.

Es toda esta capacidad y finezza investigadora la que continúa desarrollando en la actualidad y de la que quisiera mencionar, por la relevancia del objeto del análisis, el estudio del manuscrito zero (1633-1634), en colaboración con Juan María Montijano (Universidad de Málaga) y Diego
Maestri (Università degli Studi Roma Tre), ejemplar custodiado en el archivo de San Carlo alle Quattro Fontane donde se recogen las primeras intervenciones de Francesco Borromini en el citado convento. Esperamos el momento de descubrir y deleitarnos con el alcance de la nuevas investigaciones en esta línea de trabajo de la profesora Camacho, quiero reiterar maestra y amiga.

\title{
Rosario Camacho y el arte contemporáneo: episodios
}

\author{
María Jesús Martínez Silvente \\ Universidad de Málaga
}

La primera vez que me encontré a Rosario Camacho en una inauguración de arte contemporáneo fue cuando estudiaba cuarto de carrera. Recuerdo que me extrañó verla.

- ¿Esta no es la profesora de Barroco? -le pregunté a Antonia Amor, mi compañera de banca.

- Sí, tía, es Charo -afirmó con las cejas arrugadas en señal de asombro.

Se trataba de la exposición de Xul Solar en la sala de exposiciones del Palacio Episcopal, allá por el año 98. Yo todavía no era consciente de la multiplicidad de caras que formaban el prisma de la Camacho, interesada tanto en las manifestaciones pasadas como en las presentes, en la arquitectura como en la escultura, en la pintura como en las artes decorativas.

Las grandes figuras de la historia del arte contemporáneo -Pablo Picasso, Paul Gauguin, etc.- fueron analizadas por la profesora Camacho, demostrando que el estudio del arte es acumulativo, que no hay que elegir entre un período u otro, que puede llegarte con la misma intensidad una obra de Caravaggio y una de Pollock, que una iglesia románica puede resultarte tan bella como un puente de $\mathrm{Ca}$ latrava... y que no pasa nada.

A la familia de artistas de nuestra ciudad, con los que seguro vivió 
experiencias y compartió aprendizaje -José Hernández, Antonio Jiménez, Enrique Brinkmann, Manuel BarbadiIlo, Francisco Peinado, etc.- también dedicó parte de sus investigaciones, interesándose en difundir su producción en prensa, catálogos y revistas de creación.

Comprometida con el patrimonio contemporáneo local, Rosario Camacho escribió "Una demolición anunciada. El Silo de Málaga», en el Anuario de San Telmo (2006) para protestar enérgicamente por esta bárbara intervención que tuvo lugar hace unos pocos años. Podía verse a la profesora, cámara en mano, bien temprano los domingos fotografiando el edificio para, a su manera, conservarlo de algún modo.

Asimismo, se preocupó por reivindicar la importancia de la arquitectura modernista en Melilla, su ciudad natal, al igual que por ejemplos de la "arquitectura del relax" del Torremolinos de los 60 , cuando en plena dictadura, era un punto de encuentro para la modernidad europea. "La concreción de la metáfora. El bazar Aladino de Torremolinos» o «El Eclecticismo en la arquitectura religiosa de Melilla» son algunos ejemplos de estos textos -el primero perteneciente al Congreso El barco como metáfora visual (19) y el segundo a un artículo del Boletín de Arte del Departamento, que dirigió hasta fechas muy recientes-.

En el año 2000, Juan Antonio Ramírez expuso en la Sala de Arte Moreno Villa sus latas cortadas y dobladas, acompañadas del catálogo Tratado de Latoflexia y Latotomía, y de un taller donde cualquiera que se acercara podía convertir latas de atún en cangrejos o erizos, con unos instrumentos que allí mismo facilitaban. Charo fue una de las alumnas de Juan Antonio. Sentada, rodeada de niños, atendía con interés infantil las instrucciones necesarias para ayudar a materializar uno de los proyectos más originales del que fue su compañero más querido.

Hace mucho que no me resulta extraño ver a Rosario Camacho en las inauguraciones de arte contemporáneo, más bien al revés, es un rostro cotidiano en las exposiciones de nuestra ciudad. $Y$ he sido yo la que, a veces, he comentado ante la extrañeza de algún alumno:

-Sí es la de Barroco, pero no solo... 